\title{
How Crisis Spurred Healthcare Innovation in Cuba
}

\section{Eapen Chacko (Queblo, Inc.)}

\section{KEYWORDS: Professional, Scientific, Technical Services, Public Administration \& Government, Health Care \& Biotech, Entrepreneurship, Innovation, Organization, Alliance Management.}

Health care is a hotly debated topic in the US -- how it's delivered, whether the government or employers pay for it, how research on promising new drugs is funded and other issues. "Innovation" is often synonymous with big expensive breakthroughs, such as a genetically personalized medicine, new imaging methods, or a technology that can perform a procedure that once was impossible.

But innovation in health care can also mean finding ways to manage when a crisis completely disrupts the established order. What happened in Cuba over a span of five decades provides a perfect case study of this kind of disruptive change. The small island was rocked by two crises: Fidel Castro's coup in 1959, which caused an embargo that cut off Cuba from international finance, and the 1991 collapse of the Soviet Union, Cuba's only trading partner, which left its coffers empty.

Beginning in 1991, Cuba funded a multi-year, multibillion dollar creation of an innovative public health system, leveraged the experience and quality of its educated medical and clinical work force, and created one of the most innovative pharmaceutical development capabilities in the developing world, all without foreign aid or access to capital markets.

How Cuba responded, re-deployed its assets and regrouped provides a great case study of how innovation can happen in a constrained environment. While Cuba's strategies have taken it in a totally different direction from the US, and while some of those strategies have been unpopular internally, Cuba today is well positioned to accelerate the development and commercialization of new health care opportunities, now that the embargo has lifted in the post-Fidel Castro era. Its story can be instructive and encouraging for entrepreneurs and companies facing their own crises.

\section{Defining Healthcare Innovation}

Innovation in healthcare means different things to different kinds of organizations: physician groups, hospitals, medical schools, and companies from medical devices, pharmaceuticals to insurance. In the case of hospitals, for example, innovations that can produce clinical and financial benefits are often process driven. Those processes could be IT data driven, such as electronic medical records; or they could be practice driven, such as the routine washing of hands to reduce rates of in-hospital infections. The understanding of the term "innovation" itself cannot be the same for all audiences and issues. ${ }^{[1]}$

Innovation, it seems to me, is fundamentally about vision. How does one see the individual or groups in a specific setting, or in the world? Are commercial relationships purely transactional? Do partnerships or joint ventures require a measure of statutory control to be successful? Vision can be acute or blurred, wide or narrow, short-sighted or far-sighted.

Dr. Steven Covey said, "We see the world, not as it is, but as we are — or, as we are conditioned to see it."

Medtronic plc, with almost $\$ 30$ billion in revenue, is one of the global leaders in medical devices. This business giant literally began in a garage, spawned by the fundamentally different vision of the human body held by co-founder Earl Bakken. He viewed the body, not as a collection of organs encased in a musculoskeletal frame, but as an electrical system, which could be modulated and paced. Engineer Bakken also saw the world of his customer, the cardiac surgeon, in a fundamentally new way that which led to millions of patients receiving implantable pacemakers and defibrillators, leading longer and higher-quality lives. By 2019, the electrophysiology products business will amount to some $\$ 4$ billion, growing at $10 \%$ annually. These global business sprang from that original vision of Medtronic's founders. 
In Cuba's case, innovation was born of necessity: the need to adapt after access to foreign currency was completely cut off. After the 1962 U.S. economic embargo of Cuba, the country became reliant on trade and subsidies from the former Soviet Union, amounting to some $\$ 4-5$ billion annually. With the collapse of the former Soviet Union in 1991, these monies disappeared and the government of Cuba found its foreign exchange coffers dry. As a business owner once told me, "Nothing focuses the mind like an empty cash drawer."

Cuban government officials, scientists, physicians, and public health practitioners had to find a different way to fund the public health system, expand community health programs in rural areas, and develop new drugs -- a multi-year, multi-billion-dollar effort. Their strategy to was to export the services of their work force, particularly their clinical and medical personnel, to earn precious foreign exchange, then reinvest substantial surpluses into innovative models of care and drug development. And because the US in 2016 relaxed its embargo against Cuba, the island is now well positioned to harness what it built during times of scarcity and take advantage of entrepreneurial opportunities through partnering with foreign companies, clinical research organizations and scientific institutes.

\section{Political and Economic Background}

During the 1950s, Cuba was a playground for American financiers, socialites, and celebrities like Frank Sinatra and Ava Gardner. At one point, Americans held majority ownership in Cuban mining, its utilities, sugar plants, and a $25 \%$ stake in deposits of the Cuban banking system. Havana had a sophisticated, international music and cultural scene, which also spawned some unwanted cultural byproducts like prostitution. "Havana was then what Las Vegas has become," according to University of North Carolina at Chapel Hill historian Louis Perez.

The overthrow of the corrupt dictatorship of President Fulgencio Batista by Fidel Castro's 1959 revolution stirred much optimism among all economic classes and income groups in Cuba. But then, President Castro nationalized US properties and denounced foreign economic and cultural influences as imperialist. Optimism faded; former partners were soon viewed as adversaries; exports of Cuba's innovative music and culture to the US stopped suddenly. In Cuba, music played in public was ordered to have more of a "Revolutionary" character. ${ }^{[2]}$
Immediately after the Cuban Revolution, about twothirds of the 6,300 physicians on the island lived in Havana and its environs. About half of the nation's hospital beds were said to be in Havana, which was home to a single university hospital and only one rural hospital on the entire island.

With nothing approximating a public health system, basic health indicators like life expectancies, infant mortality and deaths from cancers, for example, put Cuba in Third World status for public health. Castro had alienated the US, the largest supporter of global public health; US support for global public health has amounted to some $\$ 10$ billion annually in recent years. Only the Soviet Union remained as a trading partner of Cuba, and when it fell in 1991 Cuba lost all of the foreign currency it needed to fund its health initiatives.

\section{Generating Cash for a Public Health System}

Because of the severe foreign exchange shortages, the Cuban government had to find a way to achieve its public health objectives.

Using the umbrella of Latin American and Caribbean cooperation in groups such as the Organization of American States, and the Pan American Health Organization/World Health Organization, countries in the region began working together driven by their common economic needs and the benefits of cooperation.

The Cuban government decided to trade its human capital in medicine to raise foreign exchange. First, Cuba expanded its capacity to train doctors and nurses, then sent this highly trained staff to countries in West and Central Africa, for example, which had little or no medical care in rural areas. In turn, Cuban medical schools accepted African candidates for training, and these expenses were, in turn, supported by international private foundation and multilateral agency grants.

According to the Wharton School, "Professional services carried out by Cuban doctors and nurses-who number some 37,000 working in 77 countries---are generating foreign exchange to the tune of $\$ 8$ billion a year, Cuban officials say." ${ }^{[3]}$

Venezuela, a member of OPEC, controls some 300 billion barrels of proven petroleum reserves, and its annual petroleum exports account for $\$ 36$ billion in 
value, accounting for $95 \%$ of Venezuela's exports (OPEC, 2015). Awash in foreign exchange with high oil prices, President Hugo Chavez signed an agreement with Fidel Castro in 2000 to fund $\mathbf{4 3}$ medical centers in Venezuela that would treat patients free of charge.

Also, as part of the agreement, Cuba would station some $30,000-40,000$ new physicians in Venezuela. ${ }^{[4]}$ Venezuela provided oil exports of some 90,000 barrels per day to Cuba in exchange. The Cuban physicians and staff were provided housing and modest salaries. To further support for its own health system infrastructure, equipment imports and research, Cuba taxed the foreign salaries of Cuban medical staff at rates that were effectively punitive after adjusting for currency conversion.

There is no doubt that the Cuban program in Venezuela, known as "Barrio Adentro," saved millions of lives and helped improve public health outcomes. And, while every medical professional serving in this program had to have a sense of personal mission to be effective, it is also clear that this program was very expensive $(\$ 29$ billion spent by the Petroléos de Venezuela from 2003-2015) and the incentives for the medical mission were muddled with foreign aid motives. Fifty years of development economics have shown that foreign aid programs rarely achieve their stated goals, and often create significant externalities. ${ }^{[5]}$ The applicability of this model to other emerging economies is therefore limited.

The Cuban government, as part of its own vision of international cooperation ("South-South Cooperation") incorporated into the constitution, has been sending its physicians on multi-year assignments to Ethiopia, Liberia, The Gambia, Haiti, and other countries, while asking for no quid-pro-quo.

So, Cuba has leveraged one its great tradable resources, human professional services, into missions that are consistent with the country's constitution and commitment to quality care for all. This is innovative use of the country's factor endowment of human capital in a severely constrained environment. We've described exports of professional services, in economic jargon, but where were some of the earned foreign exchange monies reinvested? Cuba used it to create a public health system for its population and a national pharmaceutical research and development infrastructure.

\section{The Next Phase: Reaching Rural Communities}

Medical practice in America is built around big arsenals of weapons against all chronic and acute conditions-high tech diagnostics, a bevy of the world's best specialist physicians who are the stars of the system, high tech surgical and interventional procedures for treating cardiovascular disease, a growing effort in oncology built on multiple approaches to cancers, and a pharmaceutical armamentarium from the world's leading drug companies, costing hundreds of billions of dollars provided by the companies' shareholders.

Cuba, in contrast, decided to make the family practice physician the center of a patient's care. Family practice, a successor to the old "general practitioner," has not been popular among college graduates entering US medical schools. Supporting specialties would be located near or in the same clinic, which was located as to give coverage to isolated, rural areas. The vision for this radically different approach was set early by Cuban authorities.

Rural medical services were expanded, and the number of rural hospitals grew from one in 1959 to 53 in 1970 . The vision of the system was to have medical care professionals embedded in local clinics where their populations lived. National medical education programs expanded rapidly to cover specialties needed for rural care, e.g. infectious diseases, especially water-borne parasites, and malaria.

Public health indicators started trending up, but the Cuban authorities believed that physician training should cover more than strict medical specialties, and so a national system of medical education was built.

Over time, Cuban physician training focused on Family Practice as a core specialty. This contrasts with the current view of the American healthcare system, where a primary care physician, often an internist, is the gatekeeper for referrals to all kinds of complex specialists.

The first generation of local clinics were plagued by long waiting times and unsatisfactory patient communications and, in some cases, substandard care because of inadequate training for medical personnel. Eventually, the system evolved to "polyclinics," where all the different specialties needed for community care 
were in one building, serving 120-150 families. Proximity of the physician specialists to one another facilitated information exchange and face-to-face discussions of patient treatment options, in lieu of the western, high tech, expensive IT-driven electronic medical records. It has been almost impossible to find dispassionate analysis and reliable statistics about how well Cuba's health services model is working.

Physicians work on a daily quota system, including house calls to patients who can't travel. Apparently, hitting the quota numbers for patients seen and meds distributed are the Cuban government's key measure of the system's success, just like factory piece work. The numbers per day reported for physicians and dentists seem unrealistic. The press has reported widespread abuse in overreporting of patients seen and medications distributed.

Public health indicators, like infant mortality, birth weights, and life expectancy seem to have improved significantly from the pre- and early post-Revolution days, but again the data are not robust, or reliably collected and validated by international sources like the WHO.

The volume of care per physician, long hours, and low pay would not work in a U.S. or developed European system. Indeed, the vision of medicine as an industrial assembly line with patients moving along it according to a timetable, turns medicine from an intensely personal encounter into a commodity, something that would be unacceptable in the US. However, making a family practice physician the center of patient care, and having the patients take accountability for their health are innovative ideas compared to current American practice. Other countries might learn from and adopt some facets of the Cuban experience as Cuba re-joins the world.

\section{Creating A World Class Cancer Drug Based on Immunotherapy}

Alongside the visioning and creation of a public health infrastructure and a national healthcare system, the government and medical community also realized that there had to be an effort to create a drug development capability for Cuba, otherwise the two systems noted above could founder for being completely dependent on high priced, global pharmaceuticals.

The Centro de Inmunologia Molecular, or (CIM) was established in 1994 to conduct fundamental scientific research with a focus on identifying targets for drug development, which would then go into a separate, business-oriented group of organizations such as Biocubafarma, established in 2013, for development and commercialization.

According to the World Health Organization, worldwide lung cancer deaths for men and women were approximately 1.6 million (2012). It was the leading cause of cancer-related deaths in Cuba and worldwide, accounting for about $19 \%$ of worldwide cancer-related deaths and $25 \%$ in Cuba. Non-small cell lung cancer (NSCLC) is the most common form of the disease, accounting for $87 \%$ of cases, and these patients at diagnosis have advanced disease about $60 \%$ of the time.

Drug development is a long, expensive, and risky proposition. In response to patent expirations on blockbuster drugs, growth of generics, and increasing pressure on prices from national health systems and volume purchasers, global pharmaceutical companies focused on becoming more productive generating blockbuster drugs. Computer technology and analytic capabilities were focused on rapidly screening more blockbuster candidates, and, hopefully, bringing them to market faster. Unfortunately, it clear that this has not worked as hoped.

Next, came the obvious Wall Street solution of rolling up drug companies by merger and acquisition into fewer players with bigger portfolios of small molecule drugs, which might cover a broader range of clinical applications. Process efficiencies and even partnerships and acquisition of startups were all supposed to yield better drug development economics. Though the jury is still out, M\&A has not yet improved drug development economics.

The average capitalized cost $(2005 \$)$ of drug development, including a fully-burdened charge for failed drugs, was estimated at $\$ 2.7$ billion. According to the National Institutes of Health, only about 3 of 10 new pharmaceutical products generate revenues equal to or greater than their average development costs.

Cancer drugs, on average, need 9 years from the start of testing in humans until they come to market; this is approximately two years longer than the average drug across all therapeutic categories. If Cuba's CIM were 
going to be a player in the global development race to "beat lung cancer" it would be virtually impossible for it to succeed against the vision of 'beating' the cancer permanently. It is this vision that drives the current US company efforts towards "personalized medicine," which in the case of cancers include drawing the patient's own T-cells, modifying them to target them more effectively to the cancer, and then reinjecting them into the patient. While conceptually appealing, this will be extremely expensive and not a front-line for most patients, especially in developing countries.

Instead, Cuban researchers from the CIM took a different approach in the 25-year development of a cancer vaccine, CIMAvax-EGF®, which is the shining example of pharmaceutical and clinical innovation in the face of seemingly crippling financial, professional, and scientific constraints due to the American embargo of Cuba.

First, Cuban researchers looked at treating cancer as a chronic condition which was to be managed, not as something to be eradicated by debilitating chemotherapy.

Cuban researchers chose a path of immunotherapy ${ }^{[6]}$, meaning that the clinical target was no longer a tumor, but rather the patient's own immune system, modulating it to a particular target or towards suppressing certain factors which inhibited the functioning of the patient's own immune system.

Global pharmaceutical companies were skeptical of this approach, both because of their own small failures along this path, and because it was inconsistent with their own clinical research strategies that directly targeted the cancerous tumors. The initial absence of the global pharma behemoths from immunotherapy meant that CIMA had the benefits of time, lower annual expenses, and opportunities for quiet cooperation with scientists at international conferences.

Cancer cells are ones that have imbalances among their many genes that control cell division (growth) and cell death (apoptosis). As the mutated cancer cells continue to grow faster they also make more copies of themselves compared to normal cells, giving them an advantage in competing for the body's energy resources.

Over time the cancer cells become immune to normal signals, and they even develop "protective" mechanisms by interfering with or disabling the body's Tcells, which normally take care of foreign cells.

A sgnificant sub-population of lung cancer patients has high concentrations of epidermal growth factor (EGF). Normal cells, and many cancer cells, have on their membranes a protein called EGFR (epidermal growth factor receptor), to which the circulating EGF binds, causing the mutated cancer cells to grow even faster, leading to tumor formation or faster tumor growth.

CIMAvax-EGF is an active immunotherapy that prevents binding of the patient's own (endogenous) circulating EGF to the EGFR by inducing the patient's own immune system to produce anti-EGF antibodies that clear the growth factor from circulation, thereby starving the tumor of growth, and in some cases actually shrinking the tumor. ${ }^{[7]}$

In 2011, CIM scientists began a research partnership with the renowned Roswell Park Cancer Institute (RPCI) in Buffalo, NY. Initial conversations between CIM and $\mathrm{RPCl}$ scientists began in 2005. To date, CIMAvax-EGF has undergone five phase I and II/trials, a randomized phase II trial, and a recently completed randomized

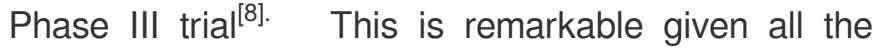
resource constraints in Cuba, and seemingly small but meaningful difficulties, such as shipping clinical packages from the U.S. to and from Cuba during the embargo.

In 2016, RPCI announced a partially randomized phase I/II study of CIMAvax with the PD-1 checkpoint inhibitor nivolumab (Opdivo® Bristol-Myers Squibb) in patients with stage III/IV NSCLC. ${ }^{[9]}$ This kind of study undertaken at a prominent US clinical oncology research and study site is pathbreaking[10], and a powerful validation of decades of Cuban work in novel, pioneering drug discovery and development. It should be noted that Cuban scientists, despite the embargo on travel, managed to benefit from independent, fundamental discoveries and studies by scientists in Japan and in the US.

As with all randomized clinical studies, the combination of the two drugs might not hit the study's 12-month survival endpoints despite some promising results thus far. But the process of innovation which led to the CIMAvax vaccine will likely continue, either by further refining the molecule or by partnering it with other companies' compounds. 


\section{Where Does Entrepreneurship Begin?}

Because of the nature of Cuba's economy, any commercial arrangements to develop CIMAvax, if there is clinical validation of its efficacy, will likely have to be under licensing or under a majority Cuban-owned joint venture. Even the process of negotiating these arrangements may take longer than usual because multiple Cuban agencies and institutes will be involved. Patience, relationship-building, and a focus on patients worldwide will benefit parties who are interesting in striking a deal for this and other vaccines and drugs that are in the Cuban portfolio. My own international experience of American companies partnering with government entities or foreign companies is that short timelines and control are highly prized, but Cuban needs and desires are quite different.

Cuba will need international assistance and cooperation to develop a robust pipeline for CIM and the emerging biotechnology industry. The Cuban partnership with $\mathrm{RPCl}$ and the thaw in relations between the US and Cuba are a source of real excitement in the international scientific community. This is a great start.

The Roswell Park study is expected to be completed in 2020.

\section{Conclusion}

We began this commentary noting that the American embargo of Cuba begun over 50 years ago has had imposed significant economic and social costs to both countries, but the impacts are more deeply felt on Cuba's much smaller economy that also suffered from some failed economic policies of its own.

Now, as international trade and finance flows potentially open, there will be gains from trade for both sides, but the potential gains to Cuba may be disproportionately large. For example, Cuba was once a major exporter of citrus and other agricultural products; for that industry to be revived, there would have to be significant economic investment to reclaim derelict lands and to get productivity to international levels. International commerce routinely deals with these problems through international corporations.

The overarching goal of the Cuban government is to encourage private ownership, but in a controlled format, $60 / 40$ on average, which means that some ventures could be more than that and some less.

The Mariel Economic Zone, which has been developed in partnership with the Chinese government, offers potential to have economic projects and activities that differ in kind and character from those on the mainland.

The Cuban government will be cautious after a halfcentury of dealing with artificial scarcities imposed by fiat. American, Chinese, Japanese, European and Indian companies are eagerly looking for partnerships in different industries, including drug development. American companies especially will have to learn patience.

At the same time, Cuban scientists recognize the need for a freer flow of money and scientific exchange with their counterparts in America, Europe and Asia. Hopefully, the Cuban government will realize that the significant potential economic benefits of opening up their system to innovation and funding from abroad will be a great boon to the Cuban people.

The world will survive and thrive without another unicorn taxi hailing service, but millions would benefit from a safe, effective cancer vaccine which is now distributed in Cuba for $\$ 1$ per dose (subsidized of course). Medical tourists from the United States can take home a year's worth of doses of CIMAvax for $\$ 5,000$. But you get the point.

Let's hope the decades of healthcare innovation yield rich fruit for Cuban citizens and cancer patients around the world.

\section{References}

[1] Forbes, D. (2016, September 20). 'How can we define 'innovation'?. Entrepreneurship \& Innovation Exchange. Retrieved April 5, 2017, from https://eiexchange.com/content/205-how-can-we-defineinnovation

[2] A wonderful animated film, "Chico y Rita," paints a picture of pre-Revolution Havana and the major cultural dislocations imposed by Castro's new government. For a current view of a Cuban exile returning home, see José de Cordoba, 2017. "The Buried Train and the French Teacher's Daughter: A Cuban Exile's Search for Home," The Wall Street Journal, 30 March 2017.

[3] How Cuba's Health Care Sector Aims to Gain a Greater Foothold. Knowledge@Wharton (2015, 
February 12). Retrieved from http://knowledge.wharton.upenn.edu/article/how-cubashealth-care-sector-aims-to-gain-a-greater-foothold/ (The figure for foreign exchange earned could not be verified)

[4] Ceaser, M., 2004. "Cuban Doctors Provide Care in Venezuelan Barrios," Lancet (363: 1874-1875) See also, Wyss, J. (2017, January 27). "Dumping medicine, faking patients: Cuban doctors describe a system that breeds fraud. Miami Herald.

[5] Edwards, S. (2014, November 24). "How effective is foreign aid?". Retrieved April 6, 2017, from https://www.weforum.org/agenda/2014/11/how-effectiveis-foreign-aid/

[6] Couzin-Frankel, J. (Science Magazine, 2013, December 20). Cancer Immunotherapy.

[7] The experience of one American patient who has survived six years on CIMAvax, showing evidence of shrinking existing tumors is documented at www.pbs.org/newshour/bb/cuban-lung-cancer-druggiving-u-s-patients/hope

(http://www.pbs.org/newshour/bb/cuban-lung-cancerdrug-giving-u-s-patients/hope) May 9, 2017.

[8] Rodriguez, P. C., MD., et al. (2016). A Phase III Clinical Trial of the Epidermal Growth Factor Vaccine CIMAVax-EGF as Switch Maintenance Therapy in NonSmall Cell Lung Cancer Patients. Retrieved April 6, 2017, from http://clincancerres.aacrjournals.org/content/clincanres/ early/2016/05/27/1078-0432.CCR-15-0855.full.pdf

[9] CIMAvax Vaccine and Nivolumab in Treating Patients with Stage IIB-IV Non-Small Cell Lung Cancer. (2016, November 2). Retrieved April 6, 2017, from https://clinicaltrials.gov/ct2/show/NCT02955290

[10] Raedler, L. A., Ph.D., R.Ph. (2015). US-Cuban Partnership Developing Anticancer Vaccine.

Additional Search Terms: entrepreneurship courses, teaching ideas, teaching resources, classroom ideas, entrepreneurship classes, business schools, business school classes, entrepreneurship students, professors 